\title{
Analisis Timbulan Lumpur dan Kualitas Lumpur Hasil Proses Pengolahan Air Bersih di WTP Kampus IPB Dramaga Bogor
}

\section{(Analysis of Sludge Generation and Sludge Quality As a Result of Water Treatment Process in WTP at IPB Campus Dramaga Bogor)}

\author{
Anastasia Elissa $^{1^{*}}$ dan Satyanto Krido Saptomo1 \\ ${ }^{1}$ Departemen Teknik Sipil dan Lingkungan, Fakultas Teknologi Pertanian, Institut Pertanian Bogor. \\ Kampus IPB Dramaga, PO BOX 220, Bogor, Jawa Barat Indonesia \\ *Penulis korespondensi: anastasia.elissa@gmail.com
}

\begin{abstract}
IPB University Dramaga has three units of WTP, two units at WTP Ciapus and one unit at WTP Cihideung. WTP produce sludge from alum coagulant and were disposed directly into water bodies. The purpose of this study were to identify the volume and characteristics of the sludge generation, comparing the sludge quality with regulations, and provide alternative recommendations for sludge management. Sludge samples were taken from effluent of clarifier and filtration. The sludge generated in the WTP Ciapus 1 was $18.63 \mathrm{~kg} /$ day while in the WTP Cihideung was $85.51 \mathrm{~kg} /$ day. The characteristics of the sludge produced were liquid and inorganic. The sludge pH of some samples in WTP Ciapus did not met the quality standards. Temperature, concentration of COD, iron (Fe), and aluminum (Al) fulfilled the quality standards. The sludge from WTP IPB Campus can be processed by collecting and drying. Dried sludge can be used as compost and the backwash residue can be recycled.
\end{abstract}

Keywords: coagulant, compost, quality standard, sludge management, water treatment plant

\section{PENDAHULUAN}

Setiap instalasi pengolahan air memproduksi hasil sampingan berupa residu dari berbagai macam proses pengolahan (Qasim et al. 2000). Kampus IPB Dramaga mempunyai tiga Instalasi Pengolahan Air Bersih (water treatment plant - WTP), yaitu 2 unit WTP Ciapus dan WTP Cihideung. Proses penjernihan air yang terjadi pada WTP dengan menambahkan bahan pejernih aluminium sulfat atau poly aluminium chloride (PAC). Penambahan zat kimia (koagulan) pada proses koagulasi dilakukan untuk mempercepat pengendapan partikelpartikel kecil di dalam air dan menghasilkan lumpur. Lumpur ini umumnya mengandung berbagai macam mineral dan materi organik yang berasal air baku dan residu senyawa koagulan yang digunakan dalam proses pengolahan (Babatunde dan Zhao 2007 dalam Adityosulindro et al. 2013).

Lumpur yang dihasilkan dari proses pengolahan air baku menjadi air bersih di WTP Ciapus dan WTP Cihideung langsung dibuang ke badan air Sungai Ciapus dan Cihideung. Menurut penelitian Adityosulindro et al. (2013), hal ini dapat mengakibatkan ancaman potensial terhadap kehidupan akuatik ketika residu disalurkan langsung ke badan air yang memiliki debit kecil, karena dapat membuat lumpur terakumulasi pada titik pembuangan. Penanganan limbah lumpur yang tepat dapat dilakukan dengan terlebih dahulu mengetahui kuantitas dan karakteristik dari lumpur yang dihasilkan dari pengolahan 
tersebut melalui proses analisis (Adityosulindro et al. 2013). Tujuan dari penelitian ini adalah mengidentifikasi jumlah dan karakteristik timbulan lumpur yang dihasilkan, membandingkan kualitas lumpur terhadap peraturan yang berlaku serta memberi rekomendasi alternatif penanganan limbah lumpur.

\section{METODOLOGI}

Penelitian dilaksanakan selama empat bulan dari bulan April sampai bulan Juni 2019. Dalam penelitian ini dilakukan pengambilan sampel air Sungai Ciapus dan Sungai Cihideung di titik sebelum pipa intake WTP Ciapus 1 dan WTP Cihideung untuk mengetahui kualitas air sungai serta sampel lumpur effluen clarifier dan unit filtrasi WTP Ciapus dan WTP Cihideung Kampus IPB Dramaga untuk pengujian karakteristik lumpur. Sampel kemudian diuji di Laboratorium Limbah Padat dan B3 Teknik Sipil dan Lingkungan dan Laboratorium Kimia Terpadu Institut Pertanian Bogor. Analisis sampel lumpur dengan parameter pada Tabel 1 dilakukan untuk memperoleh kualitas dan kuantitas lumpur, kemudian dilakukan perhitungan teoritis berdasarkan reaksi koagulan. Hasil uji kemudian dibandingkan dengan peraturan yang berlaku yaitu Peraturan Menteri Lingkungan Hidup Nomor 5 Tahun 2014 dan Peraturan Pemerintah No. 82 tahun 2001 (stream standard).

Alat yang digunakan pada penelitian ini adalah, spektrofotometer, $\mathrm{pH}$ meter, turbiditymeter, oven, timbangan analitik, cawan porselin, cawan petri, gelas piala, gelas Erlenmeyer, pipet ukur, pipet volume, saringan TSS, dan gelas ukur. Bahan yang digunakan adalah akuades, air sungai dari Sungai Ciapus dan Sungai Cihideung dan lumpur hasil WTP IPB.
Pengukuran jumlah massa lumpur dari unit clarifier dengan menggunakan nilai dari persamaan (1) berdasarkan Cornwell et al. (1987), Kawamura (2000), Qasim et al. (2000) dalam Adityosulindro (2013). Total produksi lumpur dihitung dengan penjumlahan dari produksi lumpur dari penambahan koagulan, lumpur akibat kekeruhan dan TSS, serta lumpur akibat penambahan senyawa kimia tambahan lainnya (Crittenden et al. 2012) pada persamaan (3), (4), dan (5). Perhitungan juga dilakukan dengan persamaan menurut Cornwell et al. (1987). Selanjutnya dilakukan perhitungan volume lumpur dengan persamaan (6).

$\mathrm{S}=(8.34 \times \mathrm{Q})(0.44 \mathrm{Al}+\mathrm{TSS}+\mathrm{A})$

$\mathrm{TSS}(\mathrm{mg} / \mathrm{L})=\mathrm{a} \times \mathrm{TU}$

Qsolid $=$ NTU $\times$ a $\times$ Q (1/detik)

Qkoagulan $=\mathrm{Al} \times \mathrm{b} \times \mathrm{Q}\left(\frac{\mathrm{l}}{\operatorname{detik}}\right)$

Qlumpur $=$ Qsolid + Qkoagulan

Volume lumpur $=\frac{\mathrm{S}}{\rho \mathrm{w} \times \mathrm{Ssl} \times \mathrm{Ps}}$

Keterangan:

$\mathrm{S} \quad=$ produksi lumpur (lbs/hari)

$\mathrm{Q}=$ debit instalasi (MGD

Qsolid $=$ produksi dry sludge dari turbidity coefficient (removal of turbidity) (kg/hari)

Qkoagulan = produksi dry sludge dari penambahan alum

Al $=$ dosis koagulan alum $(\mathrm{mg} / \mathrm{L}$, $17.1 \% \mathrm{Al}_{2} \mathrm{O}_{3}$ )

TSS = total suspended solids air baku (mg/L)

TU = kekeruhan air baku (NTU)

A = padatan bahan kimia tambahan seperti polimer/PAC $(\mathrm{mg} / \mathrm{L})$

a $=$ rasio antara $\mathrm{TSS}(\mathrm{mg} / \mathrm{L})$ dengan kekeruhan (NTU)

$\mathrm{b}=$ konstanta tipikal koagulan Alumunium sulfat: 0.26 dan PAC: 0.0489 X Al (\%) (Crittenden et al. 2012)

$\rho \mathrm{w} \quad=$ massa jenis air $\left(\mathrm{kg} / \mathrm{m}^{3}\right)$ 


$$
\begin{array}{ll}
\text { Ssl } & =\text { specific gravity lumpur } \\
\text { Ps } & =\text { persen padatan solid }
\end{array}
$$

\section{HASIL DAN PEMBAHASAN}

\section{Pengolahan air baku di WTP Kampus IPB Dramaga}

Pengolahan air bersih di kawasan

IPB dilakukan dengan dua water treatment plant (WTP) yaitu WTP Cihideung dan WTP Ciapus yang berasal dari Sungai Cihideung dan Sungai Ciapus. WTP Cihideung IPB memiliki 5 instalasi pengolahan dengan 4 instalasi tipe tekan dengan debit 12.5 liter/detik dan 1 tipe ultrafiltration (UF) dengan debit 10 liter/detik. WTP Ciapus memiliki 2 buah instalasi pengolahan tipe gravitasi dengan kapasitas WTP Ciapus 1 sebesar 10 L/detik. WTP Cihideung menggunakan koagulan jenis poly aluminium chloride (PAC) cair $10 \%$ dengan penggunaan umumnya 14 $\mathrm{kg}$ dilarutkan dalam 200L air dalam tangki koagulan dengan dosing 0.02 $\mathrm{mL} / \mathrm{L}$, sedangkan pada WTP Ciapus adalah aluminium sulfat atau tawas $\left(\mathrm{Al}_{2}\left(\mathrm{SO}_{4}\right)_{3} .18 \mathrm{H}_{2} \mathrm{O}\right)$ jenis $\mathrm{Al}_{2} \mathrm{O}_{3}$ minimal $17 \%$ dengan penggunaan umumnya 25 $\mathrm{kg}$ dilarutkan dalam 200L air dan dapat diubah sesuai dengan kondisi sungai.

Lumpur yang terakumulasi pada bak sedimentasi atau clarifier dibuang secara teratur dengan membuka kran pembuangan lumpur. Residu unit filtrasi berupa partikel yang tersaring dibuang dengan mekanisme backwash yang biasanya dilakukan pada awal dan akhir pengoperasian instalasi.

Air sungai untuk pengujian diambil pada lokasi di dekat intake masing-masing WTP pada waktu pagi hari dengan kondisi tidak hujan. Parameter kekeruhan pada Gambar 1 dan TSS (mg/L) pada Gambar 2 berguna untuk perhitungan lumpur. Selain itu kualitas air baku Sungai Ciapus dan Sungai Cihideung juga diketahui dari nilai $\mathrm{pH}$ dan nilai suhunya. Nilai $\mathrm{pH}$ berfluktuasi dan berada pada rentang 6.95-7.80 serta cenderung berkisar di nilai $\mathrm{pH}$ netral yaitu 7. Nilai suhu menunjukkan nilai yang berkisar antara 26.3-28.0.

Sungai Cihideung memiliki kekeruhan lebih tinggi dari Sungai Ciapus berkisar sebesar $14.90-29.03$ NTU (Gambar 1). Sungai Ciapus memiliki nilai kekeruhan antara $6.56-$ 20.77 NTU. Kekeruhan disebabkan oleh partikel-partikel dan bahan-bahan terlarut di dalam air termasuk diantaranya partikulat organik dan anorganik, dan bahan tersuspensi, dan bahan-bahan terlarut yang berkontribusi terhadap warna air (Henley et al. 2000 dan Effendi 2012 dalam Noraida 2018). Pada parameter TSS, Sungai Ciapus memiliki nilai rata-rata sebesar 10.10 $\mathrm{mg} / \mathrm{L}$ lebih rendah dari Sungai Cihideung sebesar $13.98 \mathrm{mg} / \mathrm{L}$ (Gambar 2). Nilai kekeruhan dapat menghasilkan nilai turbidity coefficient melalui perbandingan dengan nilai TSS. Rasio TSS dan kekeruhan untuk Sungai Ciapus sebesar 0.88 dan Sungai Cihideung sebesar 0.74 dan dapat digunakan dalam estimasi produksi lumpur.

\section{Karakteristik fisik lumpur}

Lumpur sebagai residu pengolahan air di WTP Kampus IPB berasal dari effluen clarifier dan effluent hasil backwash filtrasi. Debit lumpur saat pengurasan lumpur dari effluen clarifier untuk WTP Ciapus sebesar $1.55 \mathrm{~L} /$ detik dan pada effluen filtrasi sebesar 9.04 L/detik, sedangkan debit lumpur effluent clarifier WTP Cihideung sebesar 15.56 L/detik. Karakteristik fisik lumpur yang diketahui berupa total solid, volatile solid, dan specific gravity lumpur ( $\mathrm{Ssl}$ ) pada Tabel 2. 
Lumpur WTP Ciapus memiliki karakteristik lumpur alum cair dengan total solid berkisar antara 0.45\%-2.20\%, sedangkan pada WTP Cihideung memiliki total solid $0.39 \%-8.31 \%$ dengan nilai rata-rata $3.17 \%$ dan termasuk ke dalam karakteristik lumpur cair menurut klasifikasi dari AWWA (2005) dalam Pramusinto (2013). Mayoritas bagian dari lumpur residu WTP adalah anorganik yang dapat ditunjukkan dari \%fixed solid yang lebih tinggi dari \%volatile solid (Ahmad et al. 2017). SSL WTP Ciapus dan WTP Cihideung memiliki nilai di bawah 1.01 $\mathrm{g} / \mathrm{mL}$ disebabkan lumpur yang cair. Menurut Tchobanoglous et al. (2004) dalam Pratiwi et al. (2015), lumpur yang berasal dari proses sedimentasi primer memiliki nilai $\mathrm{S}_{\mathrm{SL}}$ sebesar 1.02 $\mathrm{g} / \mathrm{mL}$, sedangkan menurut Qasim (1985) dalam Az-zahra et al. (2014) $\mathrm{S}_{\mathrm{SL}}$ bernilai $1.01-1.03 \mathrm{~g} / \mathrm{mL}$.

Tabel 1 Alat/acuan pengukuran parameter

\begin{tabular}{|c|c|c|c|}
\hline No & Parameter & Satuan & $\begin{array}{c}\text { Metode/alat yang } \\
\text { digunakan }\end{array}$ \\
\hline 1 & Suhu & ${ }^{\circ} \mathrm{C}$ & Termometer \\
\hline 2 & Kekeruhan & NTU & Turbidity meter \\
\hline 3 & $\mathrm{pH}$ & - & $\mathrm{pH}$ meter \\
\hline 4 & $\mathrm{COD}$ & $\mathrm{mg} / \mathrm{L}$ & SNI 6989.2:2009 \\
\hline 5 & TSS & $\mathrm{mg} / \mathrm{L}$ & SNI 06-6989.3:2004 \\
\hline 6 & Alumunium & $\mathrm{mg} / \mathrm{L}$ & USEPA Method 3050 B \\
\hline 7 & $\mathrm{Fe}$ & $\mathrm{mg} / \mathrm{L}$ & USEPA Method $3050 \mathrm{~B}$ \\
\hline 8 & Total solid (TS) & $\%$ & SMWW 2540-G \\
\hline 9 & Spesific gravity & $\mathrm{g} / \mathrm{mL}$ & SMWW 3710-F \\
\hline
\end{tabular}

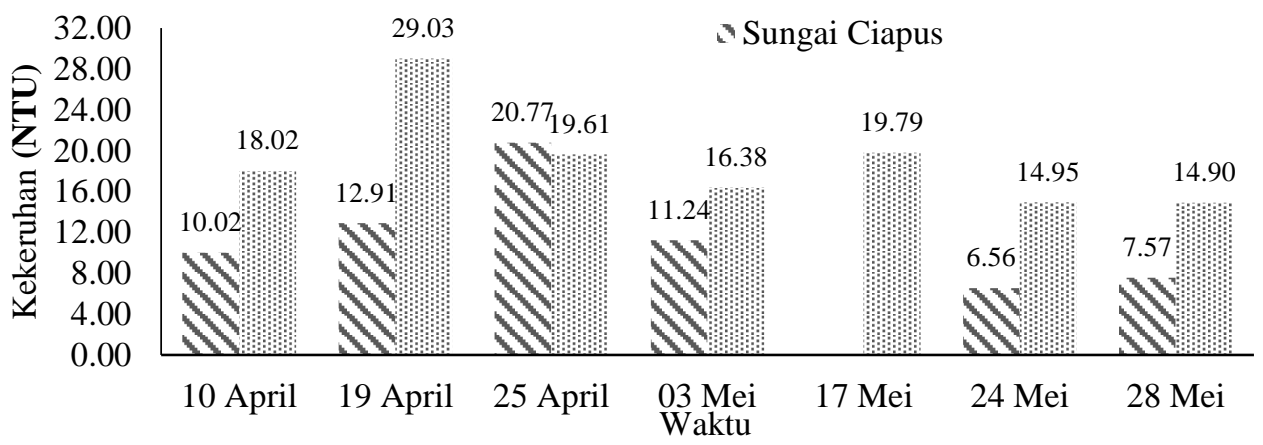

Gambar 1 Kekeruhan air Sungai Ciapus dan Sungai Cihideung

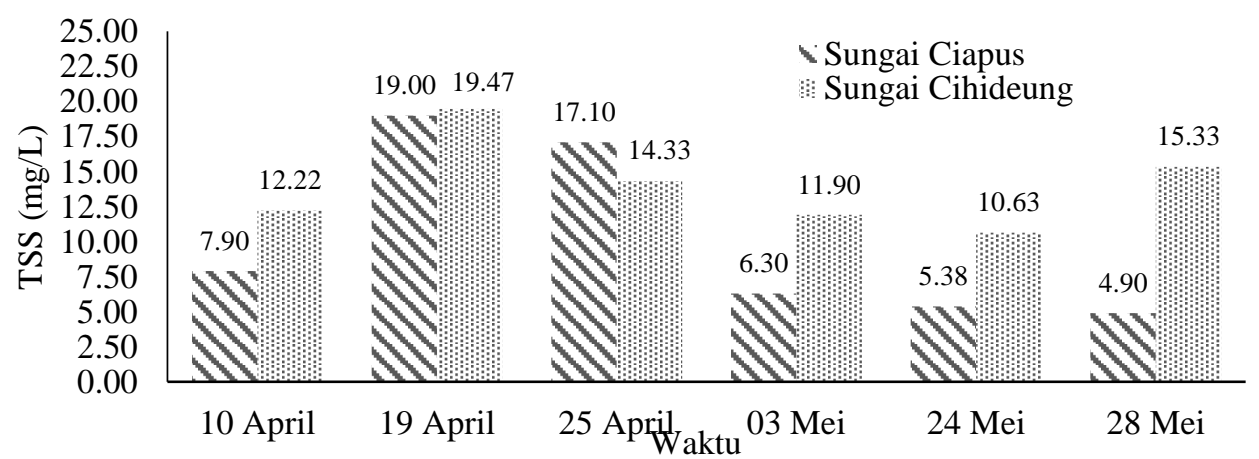

Gambar 2 Nilai TSS (mg/L) air Sungai Ciapus dan Sungai Cihideung 


\section{Timbulan lumpur}

Produksi residu untuk lumpur hasil koagulasi dapat diestimasi berdasarkan kualitas air baku dan jenis pengolahan bahan kimia. Estimasi produksi lumpur harian disajikan pada Tabel 3 dengan fluktuasi massa lumpur dengan persamaan Cornwell et al. (1987) disajikan pada Gambar 3. Volume lumpur juga dapat diperoleh berdasarkan hubungan massa lumpur dan volume lumpur pada Tabel 4 dan Gambar 4.

Produksi lumpur WTP Cihideung diketahui lebih banyak dari WTP
Ciapus 1 untuk per unitnya, hal ini dapat terjadi karena Sungai Cihideung memiliki nilai TSS (mg/L) dan kekeruhan yang lebih tinggi dari Sungai Ciapus sehingga dapat diketahui dalam rumus empiris yang digunakan dalam perhitungan produksi lumpur sebanding dengan kualitas air baku. Terdapat peningkatan produksi massa lumpur pada bulan April dan cenderung menurun di bulan Mei, hal ini dapat terjadi akibat kondisi cuaca yang masih dalam musim hujan dan menyebabkan kekeruhan yang cukup tinggi.

Tabel 2 Karakteristik fisik lumpur

\begin{tabular}{lccc}
\hline \multirow{2}{*}{ Parameter } & \multicolumn{3}{c}{ Lumpur residu } \\
\cline { 2 - 4 } & WTP Ciapus 1 Clarifier & WTP Ciapus 1 Filtrasi & WTP Cihideung Sedimentasi \\
\hline Total solid $(\%)$ & 1.27 & 0.32 & 3.17 \\
Volatile solid $(\%)$ & 21.61 & 25.79 & 21.03 \\
Fixed solid $(\%)$ & 79.15 & 74.21 & 78.97 \\
Specific gravity & 1.007 & 0.998 & 1.009 \\
(Ssl) & & & \\
\hline
\end{tabular}

Tabel 3 Produksi lumpur WTP Ciapus 1 dan WTP Cihideung

\begin{tabular}{|c|c|c|c|}
\hline \multirow{3}{*}{ Rumus empiris } & \multicolumn{3}{|c|}{ Produksi lumpur (kg/hari) } \\
\hline & \multirow{2}{*}{ WTP Ciapus 1} & \multicolumn{2}{|c|}{ WTP Cihideung } \\
\hline & & per unit & 4 unit \\
\hline Cornwell et al. (1987) & 18.63 & 21.27 & 85.06 \\
\hline Crittenden et al. (2012) & 14.70 & 24.11 & 96.45 \\
\hline
\end{tabular}

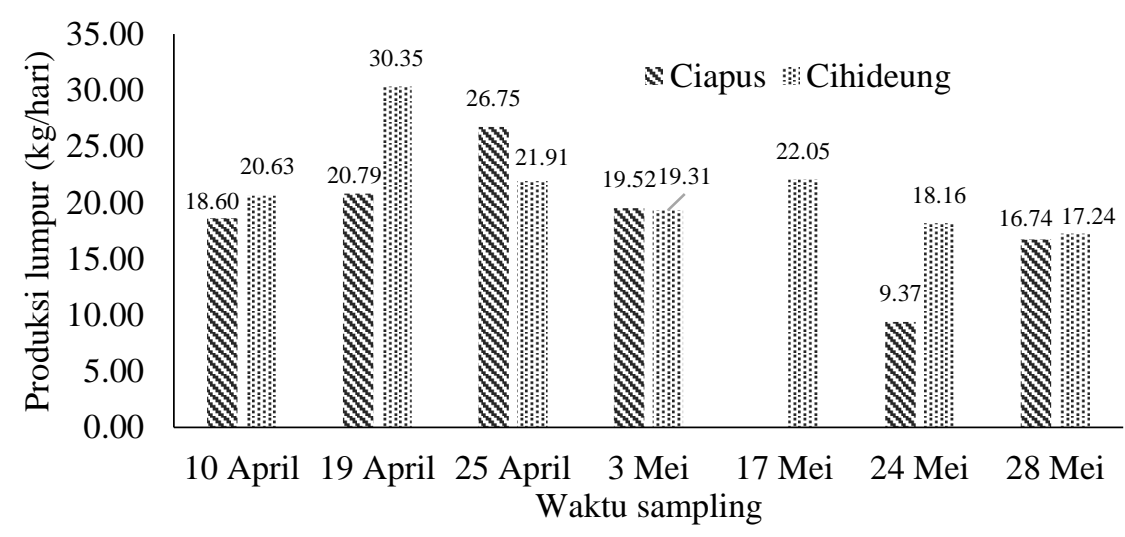

Gambar 3 Produksi lumpur WTP berdasarkan turbidity coefficient 
Tabel 4 Volume lumpur rata-rata WTP Ciapus 1 dan WTP Cihideung

\begin{tabular}{cccccc}
\hline WTP Sungai & $\begin{array}{c}\text { Berat lumpur } \\
(\mathrm{kg} / \text { hari/unit })\end{array}$ & $\begin{array}{c}\text { Berat } \\
\text { lumpur } \\
(\mathrm{kg} / \mathrm{hari})\end{array}$ & $\begin{array}{c}\text { Volume lumpur } \\
\left(\mathrm{m}^{3} / \mathrm{har} / \mathrm{unit}\right)\end{array}$ & $\begin{array}{c}\text { Volume } \\
\text { lumpur } \\
(\% \mathrm{Q})\end{array}$ & $\begin{array}{c}\text { Volume } \\
\text { lumpur } \\
\left(\mathrm{m}^{3} / \mathrm{hari}\right)\end{array}$ \\
\hline Ciapus & 18.63 & 18.63 & 2.41 & $0.28 \%$ & 2.41 \\
Cihideung & 21.38 & 85.51 & 3.08 & $0.29 \%$ & 12.34 \\
\hline
\end{tabular}

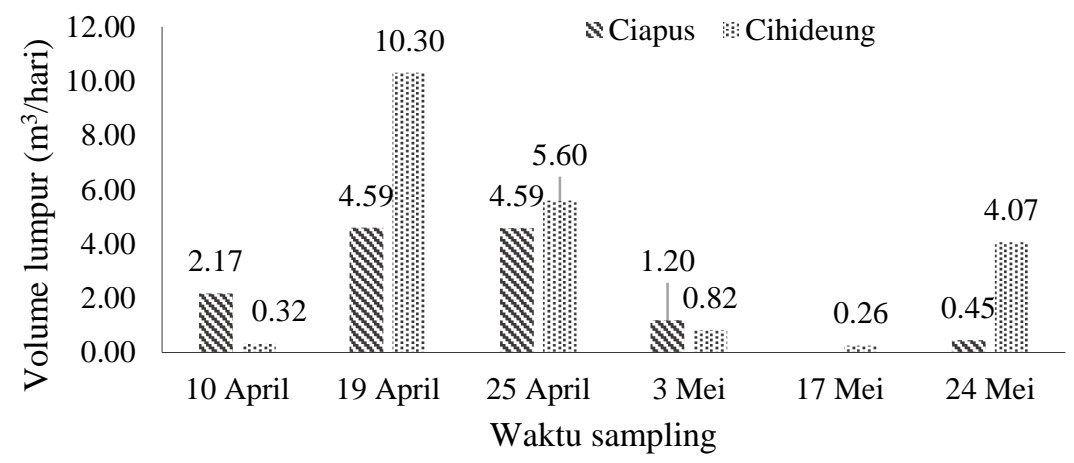

Gambar 4 Volume lumpur WTP Ciapus 1 dan WTP Cihideung

Perhitungan lumpur juga dapat dilihat dari reaksi kimia koagulan seperti pada persamaan (7) (Crittenden et al. 2012). Presipitasi yang dihasilkan diperoleh dengan perhitungan berat molekul dari $\mathrm{Al}_{2}\left(\mathrm{SO}_{4}\right)_{3}$ serta $\mathrm{Al}(\mathrm{OH})_{3}$. Endapan hidroksida yang dihasilkan bernilai cukup kecil yaitu sebesar 6.00 $\mathrm{kg} / \mathrm{hari}$ untuk WTP Ciapus 1.

Volume lumpur hasil koagulasi alumunium untuk WTP Ciapus 1 ratarata sebesar $0.28 \%$ dari total debit pengolahan sedangkan untuk WTP Cihideung sebesar $0.29 \%$ dari debit per unit pengolahannya. Fluktuasi volume lumpur per hari menunjukkan volume lumpur tertinggi terjadi pada tanggal 19 April 2019 sebesar $10.30 \mathrm{~m}^{3} /$ hari. Volume lumpur ini sebanding dengan tingginya kekeruhan yang mencapai 29.03 NTU pada WTP Cihideung.

$$
\begin{array}{r}
\mathrm{Al}_{2}\left(\mathrm{SO}_{4}\right)_{3} \cdot 14 \mathrm{H}_{2} \mathrm{O} \rightarrow 2 \mathrm{Al}(\mathrm{OH})_{3 \downarrow} \\
+6 \mathrm{H}^{+}+3 \mathrm{SO}_{4}^{2-}+8 \mathrm{H}_{2} \mathrm{O} \ldots \ldots \ldots \ldots \ldots \ldots . . .(7)
\end{array}
$$

\section{Kualitas lumpur}

Nilai $\mathrm{pH}$ dan suhu ditunjukkan pada Gambar 5 dan Gambar 6. Lumpur dari WTP Ciapus memiliki nilai $\mathrm{pH}$ berkisar 5.64-6.60 pada unit sedimentasi dan 5.57-6.64 dari unit filtrasi berada di luar baku mutu stream standard Peraturan Pemerintah Nomor 82 tahun 2001 tentang Pengelolaan Kualitas Air dan Pengendalian Pencemaran Air dan effluent standard Peraturan Menteri Lingkungan Hidup Nomor 5 Tahun 2014 sebesar 6-9. Menurut penelitian pada Cornwell et al. (1987), pH lumpur alum sebesar 5.5-7.5 sehingga masih termasuk ke dalam rentang. Lumpur yang dihasilkan dari WTP Cihideung memiliki pH sebesar 6.20-6.98 dan masih memenuhi baku mutu dan rentang nilai. Suhu lumpur yang diperoleh dari masing-masing WTP masih memenuhi baku mutu PermenLH Nomor 5 Tahun 2014 sebesar $40{ }^{\circ} \mathrm{C}$.

Kadar COD lumpur merupakan salah satu karakteristik kimia dari lumpur yang menunjukkan pengukuran 
oksigen ekuivalen dari bahan organik yang ditentukan oleh oksigen kimia (Crittenden et al. 2012) dan disajikan pada Tabel 5. Kadar COD hasil pengujian menunjukkan kadar yang cukup kecil dan memenuhi baku mutu
PP RI Nomor 82 Tahun 2001 yaitu sebesar $25 \mathrm{mg} / \mathrm{l}$ dan pada Permen LH Nomor 5 Tahun 2014 sebesar 300mg/L. Kadar besi $(\mathrm{Fe})$ dan alumunium (Al) disajikan pada Tabel 6 .

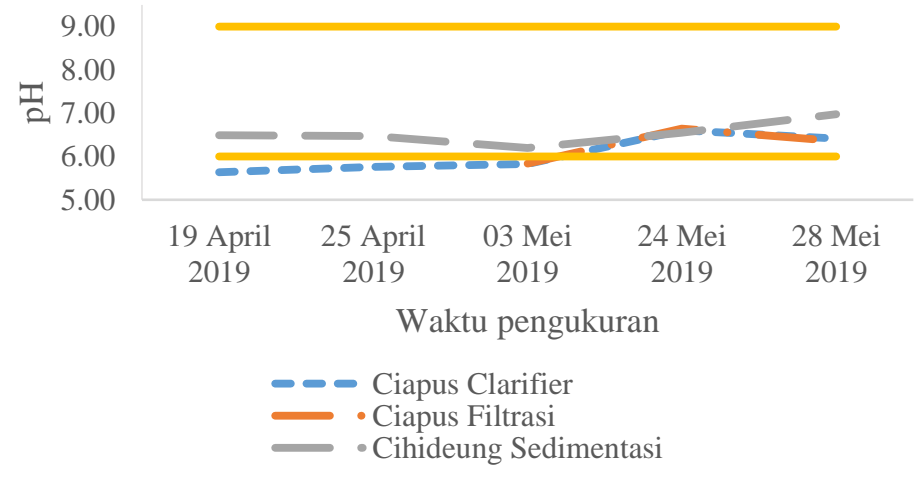

Gambar 5 pH lumpur WTP Ciapus 1 dan WTP Cihideung

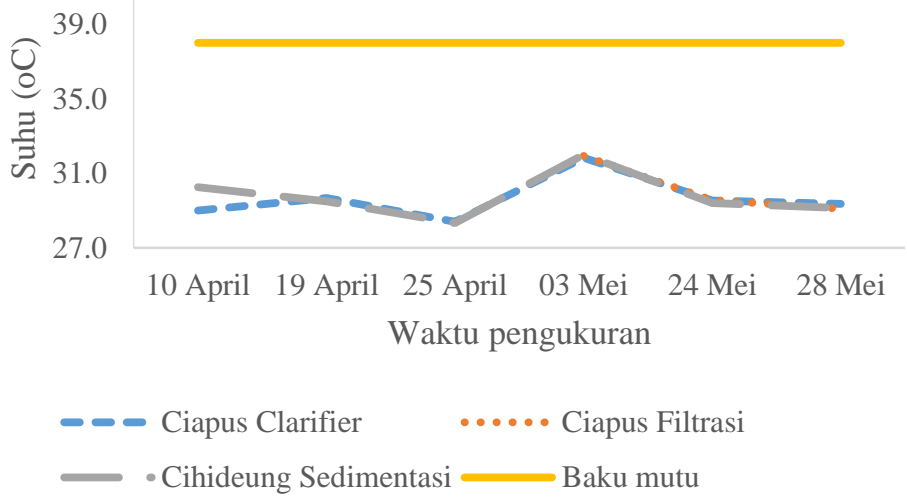

Gambar 6 Suhu lumpur WTP Ciapus 1 dan WTP Cihideung

\begin{tabular}{lc}
\multicolumn{1}{c}{ Tabel 5 Kadar COD lumpur } \\
\hline Sampl & $\begin{array}{c}\text { Kadar } \\
\text { COD (ppm) }\end{array}$ \\
\hline Ciapus & 1.67 \\
Cihideung & 4.06 \\
Ciapus Filtrasi & 0.17
\end{tabular}

Kadar Fe pada lumpur dapat berasal dari pengolahan air sungai dan dapat memengaruhi warna pada barang yang dicuci dan memengaruhi rasa dari minuman (Davis dan Cornwell 2013).
Kadar Fe pada lumpur hasil koagulasi WTP Ciapus 1 masih memenuhi baku mutu effluent standart PermenLH nomor 5 tahun 2014 sebesar $10 \mathrm{mg} / \mathrm{L}$.

Selain besi, elemen yang dapat ditemukan pada lumpur alum adalah alumunium (Crittenden et al. 2012). Kadar alumunium (Al) pada lumpur hasil koagulasi dapat berasal dari penggunaan koagulan yang mengandung alumunium. Tidak terdapat baku mutu $\mathrm{Al}$, namun kadar 
yang terlalu tinggi dapat berdampak pada manusia melalui makanan, pernapasan dan kontak dengan kulit. Selain itu, walaupun lumpur diolah pada instalasi pengolahan lumpur, kandungan alumunium akan tetap ada di dalam cake lumpur hasil olahan sebab instalasi mengolah sebatas parameter fisik (Azzahra et al. 2014).

\section{Alternatif penanganan lumpur}

Salah satu alternatif yang dapat dilakukan adalah dengan pembuatan bak penampungan yang berupa lubang besar yang digali agar dapat menapung sludge. Penampungan lumpur penting untuk menahan lumpur dalam waktu tertentu sebelum dibuang ke badan air. Selain bak penampungan, bak pengeringan juga dapat dirancang dengan kriteria volume lumpur dan kadar air.

Tabel 6 Kadar Al dan Fe lumpur WTP Ciapus 1

\begin{tabular}{lccc}
\hline \multirow{2}{*}{ Parameter } & \multicolumn{3}{c}{ Kadar } \\
\cline { 2 - 4 } & $\mathrm{mg} / \mathrm{kg}$ & $\mathrm{mg} / \mathrm{L}$ & $\%$ \\
\hline Alumunium $(\mathrm{Al})$ & 772.60 & 4.50 & 0.08 \\
Besi (Fe) & 159.06 & 0.93 & 0.02 \\
\hline
\end{tabular}

Kriteria ini ditentukan menurut SNI 7510:2011 tentang Tata cara perencanaan pengolahan lumpur pada instalasi pengolahan air minum dengan bak pengering lumpur (sludge drying bed). Lumpur dapat dikumpulkan pada penampungan lumpur sementara. Volume dan dimensi bak penampungan diperoleh sebesar $31.2 \mathrm{~m}^{3}$ dan $52.5 \mathrm{~m}^{3}$.

Volume lumpur diambil dari perhitungan volume lumpur dengan menggunakan debit lumpur sebesar 9.04 1/detik. Pada perhitungan diasumsikan panjang sama dengan lebar dengan tinggi $1.5 \mathrm{~m}$ dan $0.5 \mathrm{~m}$ freeboard sehingga diperoleh dimensi bak untuk WTP Ciapus sebesar 4.0 × $4.0 \times 2.0$ meter dan untuk WTP Cihideung sebesar $5.1 \times 5.1$ x $2.0 \mathrm{~m}$.

Berdasarkan BSN (2011), selama 15 hari kandungan air pada lumpur menjadi $60 \%$ sehingga setiap harinya dapat diperkirakan kadar air rata-rata berkurang 3\%. Persen padatan rata-rata pada lumpur Ciapus sebesar $1.27 \%$ dan pada Cihideung sebesar $3.17 \%$ sehingga diasumsikan setiap harinya saat pembuangan lumpur, padatan akan bertambah sekitar 3\% dan untuk 15 hari sebesar $45 \%$. Hal ini berpengaruh pada volume total perhitungan dimensi bak. Bak ditempatkan pada lahan kosong sekitar WTP yang berdasarkan pengamatan berupa rerumputan dan bangunan tak terpakai, dengan pertimbangan antara lain pembersihan lahan, biaya pembuatan bak, serta luas bak terhadap ketersediaan lahan.

Salah satu alternatif lainnya yang dapat dan tergolong tidak sulit dilakukan di WTP adalah pengomposan dengan lumpur residu. Berdasarkan penelitian Kurniasih (2012), lumpur dengan kandungan pencemar terutama logam berat yang cenderung tidak stabil dapat ditangani dan diolah dengan teknik pengomposan dengan jerami dan kotoran kambing yang menggunakan metode natural static pile composting. Kompos tersebut menghasilkan terjadinya penurunan kandungan logam sehingga memenuhi baku mutu.

Pada penelitian Hakim (2013), pengomposan lumpur WTP sebaiknya tidak menggunakan campuran tanah dan dicoba pada tanaman lain selain tanaman pangan. $\mathrm{Al}$ dan $\mathrm{Fe}$ yang besar berpotensi menyebabkan akar kerdil, daun kekuningan, dan pertumbuhan yang lambat. Namun kadar $\mathrm{Al}$ dan $\mathrm{Fe}$ pada lumpur WTP Ciapus 1 yang rendah masih dapat berpotensi untuk pengomposan.

Meminimalkan pembentukan lumpur dapat dilakukan dengan mengganti 
koagulan lain, menggunakan polimer yang lebih efektif pada dosis yang lebih rendah, dan bahan kimia dengan menentukan dosis optimal pada interval yang sering karena karakteristik air baku berubah (Davis dan Cornwell 2013). Hal yang dapat dilakukan pada WTP IPB antara lain adalah penentuan dosis optimum koagulan yang tepat melalui jar test secara rutin sehingga selain mengurangi endapan logam hidroksida juga dapat menghemat biaya dan menghasilkan air bersih yang kualitasnya lebih baik dan efektif.

\section{KESIMPULAN}

Simpulan penelitian ini adalah (1) timbulan lumpur yang dihasilkan di WTP Ciapus 1 pada bulan April dan Mei rata-rata sebesar $18.63 \mathrm{~kg} / \mathrm{hari}$ dengan volume lumpur rata-rata sebesar $2.41 \mathrm{~m}^{3} /$ hari. Timbulan lumpur hasil dari WTP Cihideung untuk 4 unit sebesar $85.51 \mathrm{~kg} / \mathrm{hari}$ dengan volume lumpur $12.34 \mathrm{~m}^{3} /$ hari. Karakteristik lumpur yang dihasilkan cair dan lumpur anorganik.

(2) Berdasarkan baku mutu stream standard Peraturan Pemerintah Nomor 82 tahun 2001 tentang Pengelolaan Kualitas Air dan Pengendalian Pencemaran Air dan effluent standard Peraturan Menteri Lingkungan Hidup Nomor 5 Tahun 2014, kualitas lumpur yang dihasilkan pada WTP Ciapus 1 memenuhi baku mutu untuk parameter suhu, COD, besi (Fe). Terdapat beberapa sampel yang tidak memenuhi baku mutu pH. Kadar alumunium (Al) pada sampel bernilai rendah. Kualitas lumpur yang dihasilkan unit koagulasi-sedimentasi WTP Cihideung memenuhi baku mutu parameter suhu, $\mathrm{pH}$, dan COD.

(3) Penanganan lumpur hasil WTP Kampus IPB dapat diolah terlebih dahulu sebelum dibuang ke badan air dengan proses penampungan dan pengeringan. Selain itu, lumpur dan hasil backwash dapat didaur ulang dalam pengolahan air bersih.

\section{DAFTAR PUSTAKA}

Adityosulindro S, Hartono DJ, Pramusinto AC. 2013. Evaluasi timbulan lumpur dan perancangan sistem pengolahan lumpur (studi kasus: Instalasi Pengolahan Air Minum Cibinong, Jawa Barat). Lingkungan Tropis. 7(2): 131146.

Ahmad T, Ahmad K, Alam M. 2017. Sludge quantification at water treatment plant and its management scenario. Environ Monit Assess. 189(453):1-10.

[APHA] American Public Health Association. 2005. Standard Methods of Water and Wastewater. $\quad 21^{\text {st }} \quad$ edition. Washington (US). American Public Health Association.

[AWWA] American Water Works Association. 2005. Water Treatment Plant Design, $4^{\text {th }}$ Edition. New York (US).McGraw Hill.

Az-zahra S, Rachmawati SDJ, Wardhani E. 2014. Karakteristik kualitas air baku \& lumpur sebagai dasar perencanaan instalasi pengolahan lumpur IPA Badak Singa PDAM Tirta Wening Kota Bandung. Jurnal Rekayasa Lingkungan. 2(2): 1-10.

Babatunde AO, Zhao YQ. 2007. Constructive approaches towards water treatment works sludge management: an international review of beneficial re-uses. Critical Reviews in Environmental Science and Technology. 37(2): 129-164.

[BSN] Badan Standardisasi Nasional. 2004. Cara uji padatan tersuspensi 
total (Total Suspended Solid, TSS) secara gravimetri. SNI 066989.3:2004. Tangerang (ID). Badan Standardisasi Nasional.

[BSN] Badan Standardisasi Nasional. 2009. Cara uji Kebutuhan Oksigen Kimiawi (Chemical Oxygen Demand/COD) dengan refluks tertutup secara spektrofotometri. SNI 066989.2:2009. Tangerang (ID). Badan Standardisasi Nasional,

[BSN] Badan Standardisasi Nasional. 2011. Tata cara perencanaan pengolahan lumpur pada instalasi pengolahan air minum dengan bak pengering lumpur (sludge drying bed). SNI 7510:2011. Tangerang (ID). Badan Standardisasi Nasional.

Cornwell DA, Bishop MM, Gould RG, Vandermeyden C. 1987. Handbook of practice: Water Treatment Plant Waste Management. Denver (US). AWWA Research Foundation.

Crittenden JC, Trussel RR, Hand DW, Howe KJ, Tchobanoglous G. 2012. MWH's Water Treatment: Principles and Design. $3^{\text {rd }}$. New Jersey (US).John Wiley \& Sons.

Davis ML, Cornwell DA. 2013. Introduction to Environmental Engineering. New York (US).Mc Graw Hill.

Effendi H. 2012. Telaah Kualitas `Air Bagi Pengelola Sumber Daya dan Lingkungan Perairan. Yogyakarta (ID). Kanisius.

Hakim E. 2013. Analisis up take kandungan logam berat dari kompos lumpur water treatment plant oleh tanaman [skripsi]. Bogor (ID). Institut Pertanian Bogor.

Henley WF, Patterson MA, Naves RJ, Lemly AD. 2000. Effects of sedimentation and turbidity on lotic food webs: a concise review for natural resource managers. Journal Reviews in Fisheries Science. 8(2):125-139.

Kawamura S. 2000. Integrated Design and Operation of Water Treatment Facilities. 2nd ed. New York (US). John Wiley \& Sons.

Kurniasih N. 2012. Pengomposan Lumpur Pengolahan Air dengan Limbah Pertanian [tesis]. Bogor (ID).Institut Pertanian Bogor.

Noraida. 2018. Pola penambahan larutan tawas untuk penurunan kekeruhan air Sungai Martapura. Jurnal Kesehatan. 9(2): 208-213.

Pramusinto AC. 2013. Evaluasi timbulan lumpur dan perancangan instalasi pengolahan lumpur (studi kasus: instalasi pengolahan air minum (IPAM) Cibinong, PDAM Tirta Kahuripan) [skripsi]. Depok (ID). Universitas Indonesia.

Pratiwi R, Rachmawati SDJ, Pharmawati K. 2015. Perbandingan potensi berat dan volume lumpur yang dihasilkan oleh IPA Badak Singa PDAM Tirta Wening Kota Bandung menggunakan data sekunder dan primer. Reka Lingkungan. 1(3): 111.

Qasim SR. 1985. Wastewater Treatment Plants, Design, and Operation. New York (US). CBS College Publishing,

Qasim SR, Motley EM, Zhu G. 2000. Water Works Engineering: Planning, Design, and Operation. New Jersey (US). Prentice Hall PTR.

Tchobanoglous G, Burton FL, Stensel HD. 2004. Wastewater Engineering: Treatment and Reuse. $4^{\text {th }}$ ed. New York (US). Mc Graw Hill. 